\title{
Perceived success of energy strategies for South Africa's financial services industry
}

\author{
Erika van der Westhuizen*, Jackie Young \\ Department of Finance, Risk Management and Banking, College of Economic and Management Sciences, \\ University of South Africa, Preller Street, Muckleneuk, 0003, Pretoria, South Africa
}

\section{Abstract}

Energy strategies have become a global focal point involving both individuals and organisations. These strategies are implemented widely by developed countries to address greenhouse gas emissions. Developing countries are, on the other hand, lagging behind with this important global objective of reducing emissions. South Africa is one of these countries because of its rapid industrialisation along with its increasing use of coal to produce energy. It is therefore imperative for the country to develop and implement energy strategies supported by a culture and awareness of energy management. The purpose of the present study is to create an awareness of the current state of energy strategies in terms of energy conservation, efficiency and sustainability. A quantitative research design was followed, using a questionnaire to evaluate the energy management strategies implemented by the South African financial services industry. The results indicated that there are two main barriers against their implemen-
\end{abstract}

tation: their cost, and limited awareness and knowledge of the various strategies available. The results show that renewable energy strategies are not exploited to a beneficial degree. One way to enhance the development and efficiency of renewable energy strategies is to improve communication about the benefits through training and education programmes.

Keywords: renewable energy; energy strategies; energy conservation; energy efficiency; energy risks

\section{Highlights:}

- Energy conservation and efficiency strategies assist with reducing energy costs.

- Barriers against implementation include the cost of the strategies and lack of knowledge.

- Communication improves reductions in energy costs.

Journal of Energy in Southern Africa 29(3): 66-74

DOI: http://dx.doi.org/10.17159/2413-3051/2018/v29i3a5273

Published by the Energy Research Centre, University of Cape Town ISSN: 2413-3051 http://journals.assaf.org.za/jesa

Sponsored by the Department of Science and Technology

\footnotetext{
* Corresponding author: Tel: +27 (0)12 429 4466;

email: bothae2@unisa.ac.za
} 


\section{Introduction}

Energy conservation and efficiency as well as renewable energy have become focal points in the everyday lives of individuals and organisations. Some organisations' motivations to implement energy strategies include becoming more sustainable and reducing their carbon footprints and operational costs. According to the U.S. Energy Information Administration (2013), the total consumption of marketable energy worldwide was predicted to increase by $56 \%$ between 2010 and 2040 . Keho (2016) confirmed the predictions by, indicating that the biggest increase, 46-58\%, would take place in developing countries from 2004 to 2040 This study further indicated that developing countries' energy consumption would grow at a rate of $3 \%$ per year in comparison with $0.9 \%$ for industrialised countries. Davidson et al. (2002) pointed out that South Africa was the most industrialised country in Africa and produced the most greenhouse gas (GHG) emissions, through its dependence on coalproduced energy. The U.S. Energy Information Administration (2016) indicated that Africa's total coal consumption increased by $40 \%$ for the period 2012 to 2040, with South Africa accounting for more than $90 \%$ of Africa's total consumption of energy. The primary energy supply for South Africa is shown in Figure 1. Figure 1 shows that South Africa's primary energy supply source is coal, at $67.9 \%$, with renewable energy sources only accounting for $0.3 \%$ of the total energy supply in 2015.

Figure 2 illustrates the country's energy usage per sector in 2015, indicating that the three major consumption sectors were industrial, residential and transport, which together accounted for $90 \%$ of the total energy available. The balance was consumed by commerce, agriculture and other sectors. The country prioritised the energy, transport, mining and industrial sectors for moderating actions regarding climate change and the implementation

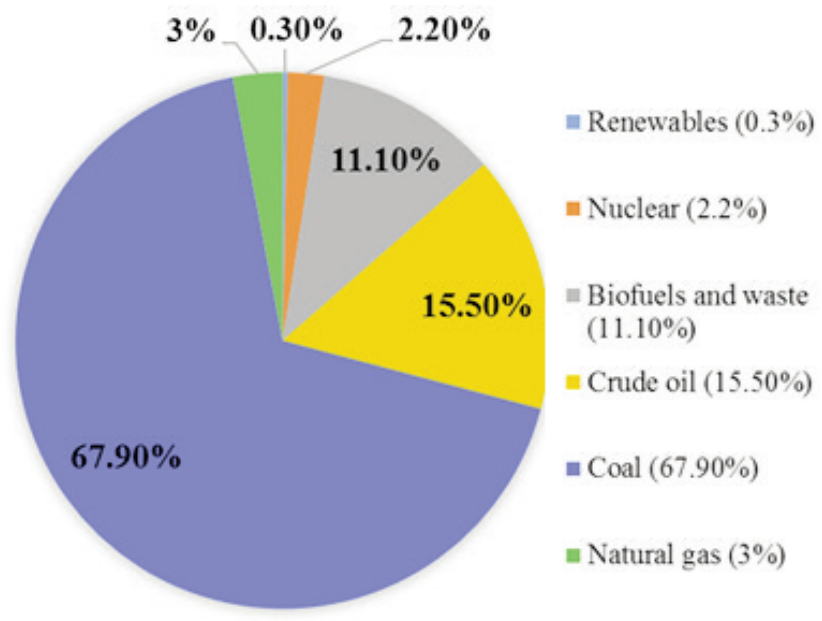

Figure 1: Primary energy supply in South Africa in 2015 (International Energy Agency, 2015). of alternative energy sources (Department of Energy, 2015), the commerce sector still showed opportunities for the implementation of additional energy management strategies to reduce energy costs and greenhouse gas (GHG) emissions.

The commerce sector's energy usage was still quite low, at $6 \%$ in 2015 , but with a potential to take the lead in energy management through energy conservation and efficiency as well as the introduction of renewable energy sources to the energy mix. These changes to the energy mix within organisations were promoted by the government through fiscal and financial incentives as well as a robust regulatory and legal framework (Department of Energy, 2016). Currently, the commerce sector's main use of energy is in the form of lighting, heating and air-conditioning, which could prove costly for large buildings especially. It is, therefore, important for organisations operating in this sector to manage energy in a way that will reduce costs, increase sustainability and lower carbon emissions.

The increase in marketable energy and the costs associated with energy create a need for organisations to implement and manage energy strategies to decrease the possible negative impact that increasing energy costs can have on them. The research question for this article was: To what extent can the energy strategies implemented by the financial services industry in South Africa ensure effective reductions in energy cost? The aim was to evaluate the country's energy strategies with respect to their efficiency and perceived success in the financial sector.

\section{Literature review}

Esty and Simmons (2011) found that organisations' interest in having a green business has increased over the last decade and the top management in most large organisations have realised that sustainable environmental issues needed to be part of an organisational strategy. Energy management can be

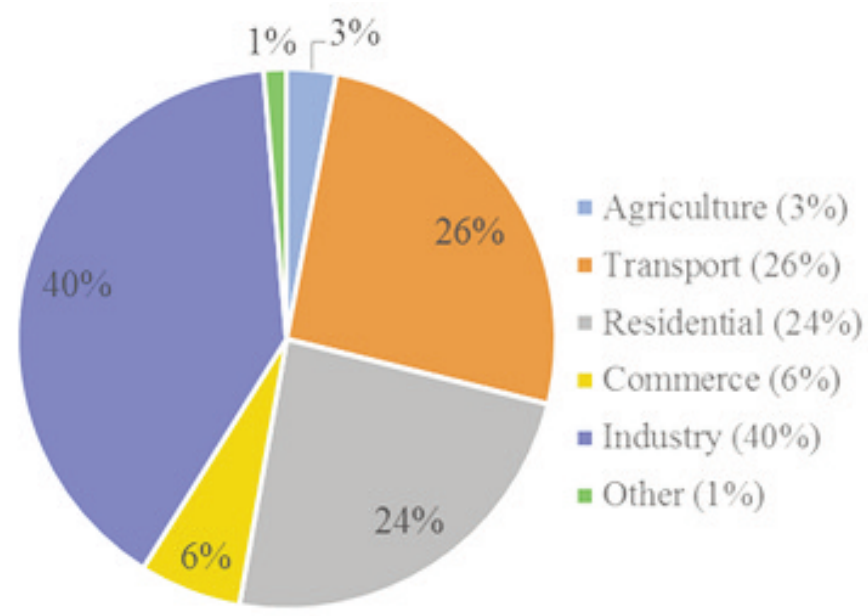

Figure 2: Energy usage by sector in 2015 (International Energy Agency, 2015). 
defined as a combination of systematic techniques, energy activities and organisational management processes in order to improve an organisation's energy performance through lower energy costs and GHG emissions (Ates and Durakbasa, 2012). The implementation of energy management can help organisations reduce the risks and costs associated with energy, to enhance their reputation and improve their level of compliance with the legislation (Energy Lens, 2014). Winkler (2005) mentioned that energy risk management could be regarded as a critical factor in both the social and economic development of South Africa.

Lund (2007) classified energy strategies into three aspects: energy conservation, energy efficien$\mathrm{cy}$, and renewable energy. It is imperative for organisations to consider implementing all three to develop a holistic energy management framework. In this regard, Fox (2009) stated that the primary objective of energy management within organisations was to provide a comfortable working environment by regulating temperature and humidity, to provide electricity for infrastructure and operations, and to provide a productive work environment using technology and various available tools.

Energy management has become a vital task of organisations because of increasing energy prices, carbon emissions targets, and legislative and regulatory requirements. Energy management incorporates three energy strategies: energy conservation, energy efficiency, and using renewable energy. Organisations reduce their GHG emissions and operational costs by developing a culture and awareness of managing energy. Successful energy management within organisations involves all three strategies.

Strategy 1: Energy conservation. This is the easiest to implement. Organisations can reduce their energy use by such actions as switching off electrical equipment not in use, and using less electricity in peak periods, therefore decreasing the demand for electricity.

Strategy 2: Energy efficiency. Energy efficiency is defined as the ratio of energy input to energy output within an organisation (Herring and Roy, 2007) and it is inversely proportional to energy consumption (Hsu, Chang and Hsiung, 2011). Energy efficiency is still seen as a low-cost solution for organisations to reduce their operational energy costs. This strategy involves both demand-side and supply-side management. The former encourages energy users to use less electricity during peak periods, although it does not always decrease energy consumption, while supply-side management, involves an organisation's energy supply, which can be managed and reduced through the introduction of a sustainable energy management system. Ways to achieve energy efficiency include (Winkler and Van Es, 2007):

- efficient lighting systems, including compact florescent lamp and light-emitting diode devices;

- lighting retrofits, including motion sensors;

- smart metering, which tracks energy consumption;

- unplugging and switching off electronics when not in use;

- programmable control systems which monitor consumption; and

- computer-intelligent software programmes to assist with the management of computer systems when not in use.

Strategy 3: Renewable energy. As the final level of the energy management pyramid, this is also the costliest of the three. Most energy supplied worldwide is produced by fossil fuels (Johansson and Thollander, 2018), which include coal, crude oil, natural gas and turf, and which are all produced from animal and plant remains under enabling conditions over an extended period (Quaschning, 2009). The use of these energy sources damages the environment by producing harmful toxins and carbon dioxide, increasing the amount of GHG emissions (Dresselhaus and Thomas, 2001).

Renewable energy means using any sustainable energy source such as solar, wind, waves and tides, hydropower or biomass, with a potential to reduce dependence on fossil fuels and with no or lower carbon emissions (Botha, 2017). Renewable energy incurs lower operating costs (Fox, 2009). It also ensures increased production of clean energy and diversification of the energy supply (Winkler, 2005). Most countries are increasing the use of renewable energy sources. In Africa, for example, Morocco, Egypt, Algeria and Nigeria plan to increase the proportion of energy generated by renewable energy sources to between $15 \%$ to $40 \%$ of their total energy use by 2030 (Cassell, 2013). South Africa's 2030 target for renewable energy sources ranges between 15\% and 29\% (Edkins et al., 2010).

Energy management strategies can assist organisations to reduce their GHG emissions by implementing renewable energy as well as energy conservation and efficiency strategies. The key benefits of all energy management strategies are to enhance energy security, protect the environment and reduce GHG emissions (Small, 2012; Russian Sustainable Energy Financing Facility, 2011). Additional benefits include possible tax rebates, lower operating costs, and an improvement in an organisation's corporate social responsibility. There are, however, also barriers to implementing such strategies, including high capital implementation costs; limited knowledge, education and awareness; limited incentives and finance; a weak services mar- 
ket; and a lack of technological support (Botha, 2017).

It is important that, in terms of the potential benefits, organisations include energy conservation, energy efficiency and renewable energy within their energy management strategies. It is also essential that organisations mitigate and control the potential barriers to energy management strategies by executing sound management decisions.

\section{Methodology}

A quantitative, non-experimental research design was followed using a questionnaire to evaluate energy management strategies implemented by South Africa's financial services industry. The target population for this research included managers involved in operations and strategic decisions in the sector. A non-probability sampling method was used that focused on the number of respondents that needed to be evaluated in order to get an indepth understanding of the research problem. There were 144 participants and 78 respondents. A response rate of $54 \%$ was achieved, which was considered to be representative and to yield reliable findings and conclusions. The data were analysed by means of descriptive and inferential statistics.

\section{Results and discussion}

The study analysed the attitudes and opinions of managers in the financial services industry represented by the banking industry, insurance companies, investment organisations, asset management entities and other related industries, including financial consulting, government, non-profit organisations, research and general financial services, as shown in Figure 3.

The focus was on the energy management strategies implemented by organisations to reduce their operating costs. It also investigated the perceived effectiveness of strategies to communicate energy management strategies to employees. Figure 4 shows the basic activities used by most respondents as part of their energy conservation strategies. It was found that $87 \%$ of respondents switched off lights when not in use, $85.9 \%$ used energy-saving light bulbs; $84.6 \%$ re-set their central heating and cooling systems; and $79.5 \%$ restricted their employees' use of portable heating and cooling systems.

The high proportions of these activities did not prevent improvement on other basic energy conservation activities such as the use of light-timing devices, which were used by less than $50 \%$ of the respondents. This could be attributed to cost implications of this activity or a lack of awareness. Out of the five energy conservation activities, the use of energy-saving light bulbs; resetting heating and cooling systems; and the restriction of portable heating and cooling systems were, respectively,

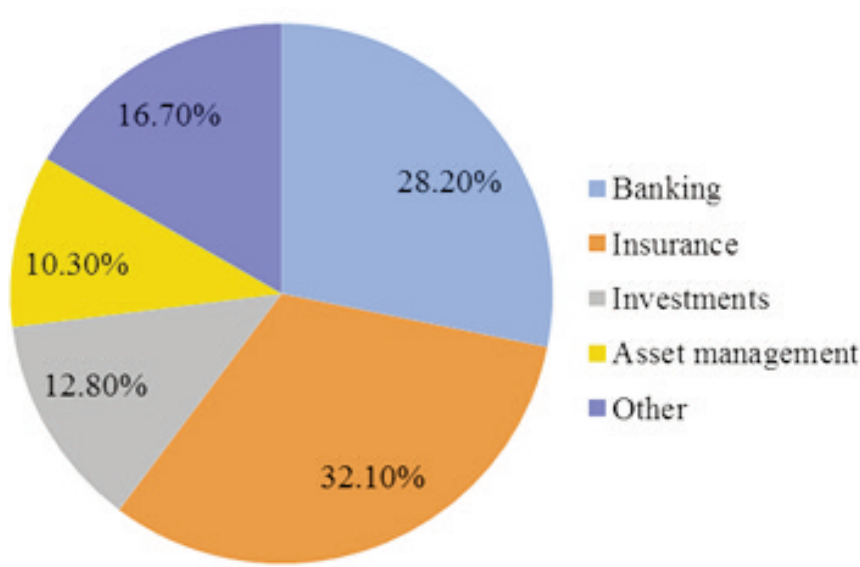

Figure 3: Industries involved in the financial services industry based on response rate.

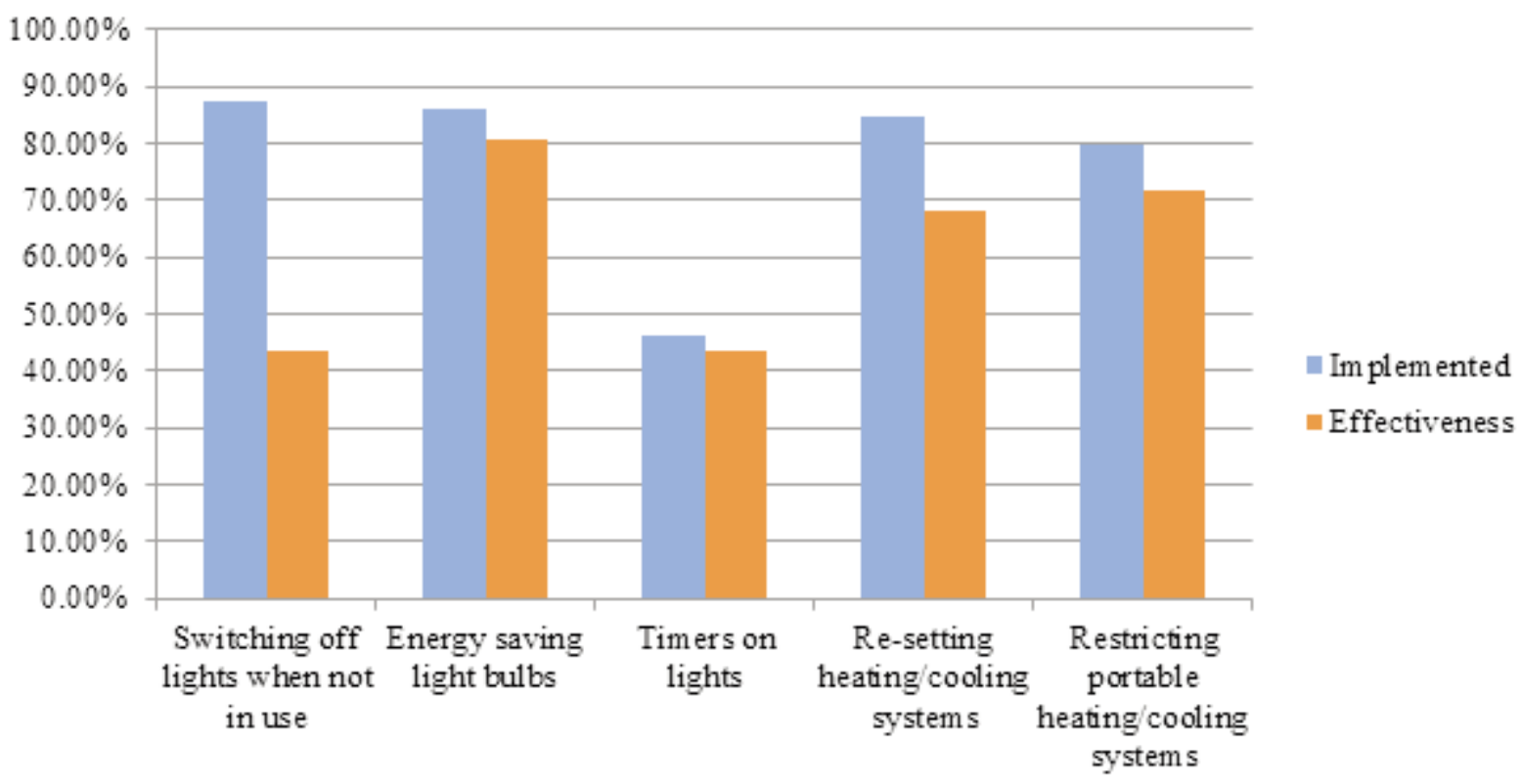

Figure 4: Energy conservation and efficiency implementation and effectiveness. 
found to be the most effective energy-saving strategies within the various organisations at 80.8, 68.0, $71.8 \%$. Switching off lights when not in use accounted for only $43.6 \%$, which could be one of the most basic energy conservation activities. The low exploitation of this energy conservation activity could be caused by the employees' lack of awareness within organisations, poor communication, or by a low appetite of employees to change.

A renewable energy strategy, as the last strategy within energy management which should form part of the organisations' overall strategy. Most of the respondents $(65.3 \%)$ did not make use of renewable energy sources. Although the reasons for not implementing renewable energy strategies did not form part of the study, possible cause for this could include the costs and finance options involved in renewable projects as well as a general lack of knowledge and awareness of these strategies. Figure 5 shows that $24.4 \%$ of the respondents used solar energy, $6.4 \%$ wind energy and $3.9 \%$ biomass. Although fewer than $35 \%$ of the organisations were implementing the various available renewable energy strategies, these were still seen as being effective in energy management and in reducing energy costs within the organisation (solar energy $21.8 \%$, wind turbines $9 \%$ and biomass $6.4 \%$ ).

Communication is a vital part of any process within an organisation. The results shown in Figure 6 show more emphasis on the communication of energy conservation and efficiency strategies than on renewable energy strategies. More than $70 \%$ indicated that communication existed with regard to energy conservation and efficiency strategies, while less than $30 \%$ indicated that these strategies were not communicated or that they were not aware of the communication attempts. With regard to renewable energy strategies, only $55 \%$ indicated that they were communicated within their organisations; $33 \%$ indicated that there was no communication of

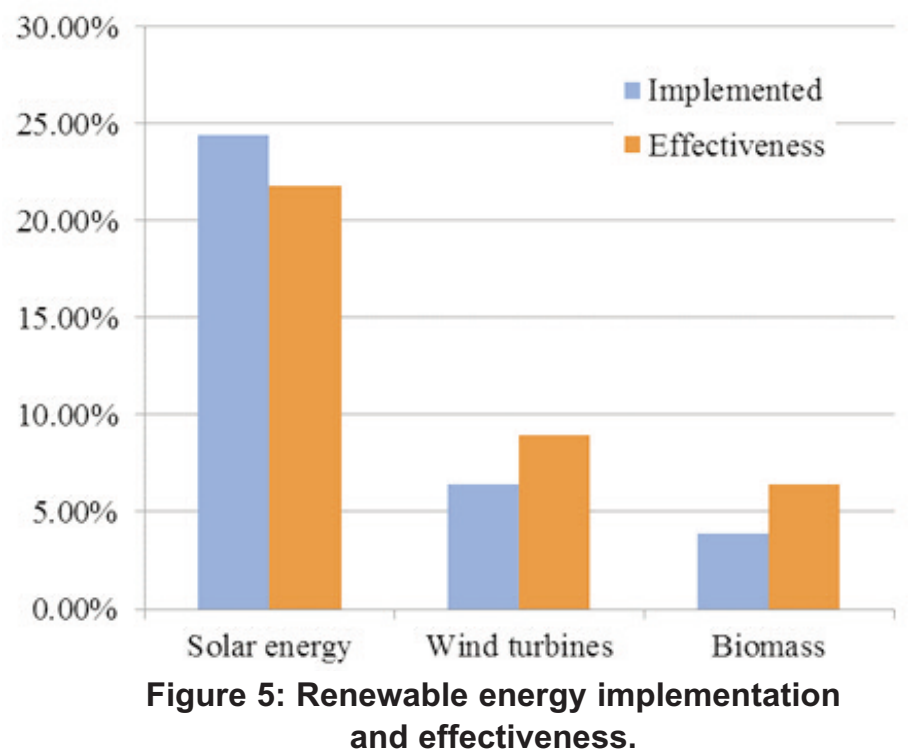

these strategies; while the balance indicated no awareness to any communication at all.

Research by Winkler and Van Es (2007) and Fox (2009) showed that funding is a barrier against the implementation of energy management strategies, but that it can assist organisations in reducing their overall operating costs. Figure 7 shows that most of the respondents $(80 \%)$ found that implementing energy conservation and efficiency strategies assisted in reducing energy costs, while $49.9 \%$ indicated that renewable energy strategies had the same effect. Only $12 \%$ indicated that their energy conservation and efficiency strategies had no influence on their costs, with $38.5 \%$ indicating that renewable energy strategies had no influence on the costs within their organisations. Nine percent indicated that they did not know whether energy conservation and efficiency strategies had a possible influence on their costs, while $12 \%$ did not know about renewable energy strategies.

The present study showed a positive attitude towards implementing energy strategies and their effectiveness within organisations. One aspect, however, that could be improved to increase cost saving for the organisations is communication with employees about the various energy strategies that the organisations are implementing. A correlation analysis was conducted to examine the potential of energy conservation and efficiency strategies; and renewable energy strategies to predict a reduction in energy costs. Existence of a strong positive correlation of $p=0.627, n=71, p<0.001$ (were $p$ is the correlation and $n$ the number of respondents) was found among implementing energy conservation and efficiency strategies and a reduction in energy costs. It was also found that a positive correlation of $p=0.370, n=71, p<0.002$ between implementing renewable energy strategies and a reduction in energy costs existed. Although the correlation for the renewable energy strategies was lower than for

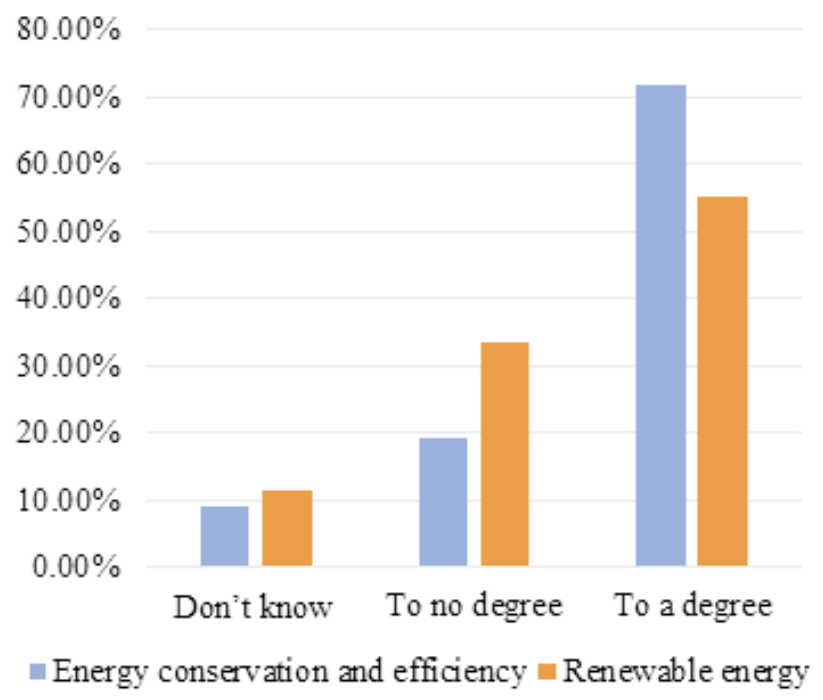

Figure 6: Communication of energy strategies. 
$90.00 \%$

$80.00 \%$

$70.00 \%$

$60.00 \%$

$50.00 \%$

$40.00 \%$

$30.00 \%$

$20.00 \%$

$10.00 \%$

$0.00 \%$

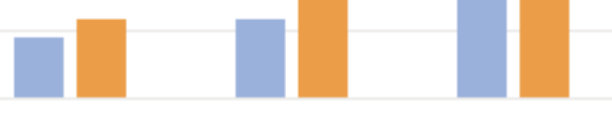

Don't know To no degree To a degree

Energy conservation and efficiency

Renewable energy

Figure 7: Reducing energy costs through implementing energy strategies

the energy conservation and efficiency strategies, both showed an increased probability of a decrease in energy costs if these strategies were implemented, as summarised in Table 1.

The results corroborated a reduction in energy costs within organisations with an increased implementation of energy strategies. The literature has also shown that implementing energy strategies not only promotes energy security, it also assists organisations to decrease their energy costs and overall carbon emissions (Russian Sustainable Energy Financing Facility 2011; Small 2012).

Multiple regression analyses were conducted to examine the relationship among the decrease in energy costs and implementing energy conservation and efficiency strategies; and communicating these strategies. The multiple regression model with both predictors produced $\mathrm{R}^{2}=0.757$, as shown in Table 2, where $\mathrm{R}^{2}$ is the proportion of variance in the dependent variable that can be explained by the independent variable. The results further indicated that the model was a significant predictor of the reduction in energy costs, where $\mathrm{F}(2,66)=99.514$, $p<0.0001$ (where $F$ is the F-ratio and $p$ the statistical significance), as shown in Table 3.

Both communication, where beta $=0.694$ and $p<0.0001$; and energy conservation and efficiency

Table 1: Summary of correlations.

\begin{tabular}{lcccc}
\hline Parameter & Reduction in & $\begin{array}{c}\text { Energy conservation } \\
\text { energy cost } \\
\text { and efficiency } \\
\text { strategies }\end{array}$ & $\begin{array}{c}\text { Renewable } \\
\text { energy } \\
\text { strategies }\end{array}$ \\
\hline Pearson & Reduction in energy costs & 1.000 & 0.627 & 0.370 \\
correlation & Energy conservation and efficiency strategies & 0.627 & 1.000 & $\mathrm{NA}$ \\
\hline Level of signif- & Renewable energy strategies & 0.370 & $\mathrm{NA}$ & 1.000 \\
icance. (2-tailed & Energy conservation and efficiency strategies & 0.000 & 0.000 & 0.002 \\
at 0.01) & Renewable energy strategies & 0.002 & $\mathrm{NA}$ & $\mathrm{NA}$ \\
\hline Number of & Reduction in energy costs & 71 & 71 & $\mathrm{NA}$ \\
\hline respondents & Energy conservation and efficiency strategies & 71 & 71 & 71 \\
\hline & Renewable energy strategies & 71 & 71 & 71 \\
\hline
\end{tabular}

Table 2: Summary of the model on the reduction in energy costs.

\begin{tabular}{lcccc}
\hline Model & $R$ & $R^{2}$ & Adjusted $R^{2}$ & Std. error of the estimate \\
\hline 1 & $0.870^{\mathrm{a}}$ & 0.757 & 0.749 & 0.632 \\
\hline $\begin{array}{l}\text { a }=\text { Predictors: (Constant), Communication of energy conservation and efficiency strategies, Energy strategies implemented; } R= \\
\text { Multiple correlation coefficient, Std. }=\text { Standard }\end{array}$
\end{tabular}

Table 3: The ANOVA ${ }^{a}$ of communication, implementation of energy conservation and efficiency strategies and reduction in energy costs.

\begin{tabular}{ccccccc}
\hline Model & Parameter & Sum of squares & $d f$ & Mean square & $F$ & Sig. \\
\hline 1 & Regression & 79.598 & 2 & 39.799 & 99.514 & $0.000^{\mathrm{b}}$ \\
& Residual & 25.596 & 64 & 0.400 & & \\
& Total & 105.194 & 66 & & & \\
\hline
\end{tabular}

$a=$ Dependent variable: Implementation of energy strategies resulted in a decrease in energy costs; $b=$ Predictors: (Constant), Communication of energy conservation and efficiency strategies, Energy strategies implemented; $d f=D e g r e e s$ of freedom, $F=F$ ratio, Sig. = Statistical significance. 
strategies, where beta $=0.278, \mathrm{p}<0.0001$, contributed significantly to the model as presented in Table 4. The final predictive model was according to Equation 1.

reduction in energy costs $=-0.178+(0.642$

$\mathrm{x}$ commumication $)+(0.375 \mathrm{x}$ strategy $)$

It can therefore be concluded that communication plays a major role in energy conservation and efficiency strategies. Decision-makers will be aware of these strategies and by implementing it will lead to a reduction in energy costs.

Multiple regression analyses were conducted to examine the relationship among the decrease in energy costs and the implementation of renewable energy strategies; and communication of these strategies. The renewable energy strategies were excluded because they did not influence the reduction in energy costs. The multiple regression model with communication as predictors produced $\mathrm{R}^{2}=$ 0.790 , as shown in Table 5 . The results further indicated that the model was a significant predictor of the reduction in energy costs, $F(1,56)=207.003$, $\mathrm{p}<.0001$ as presented in Table 6 .

The communication of renewable energy strategies contributed significantly to the model (beta = $0.864, p<0.0001$ ) (Table7). The final predictive model was according to Equation 2.

reduction in energy costs $=0.231+$

(0.864 x communication)

It can therefore be concluded that communication plays a role in renewable energy strategies and by increasing the communication regarding the energy strategies will assist in decreasing the energy cost of the organisation.

Although most of the organisations seem to be implementing various energy conservation and efficiency strategies, renewable energy strategies are still relatively rare. The results showed that with an increase in communication regarding the various energy strategies, organisations could also increase a possible reduction in their overall energy costs.

Table 4: Coefficients of communication, energy efficiency and conservation strategies and reduction in energy costs.

\begin{tabular}{|c|c|c|c|c|c|c|}
\hline \multirow{2}{*}{$\begin{array}{l}\text { Model } \\
1\end{array}$} & \multirow[t]{2}{*}{ Parameter } & \multicolumn{2}{|c|}{$\begin{array}{l}\text { Unstandardised } \\
\text { coefficients }\end{array}$} & \multirow[t]{2}{*}{$\begin{array}{l}\text { Standardised } \\
\text { coefficients }\end{array}$} & \multirow{2}{*}{$\begin{array}{c}t \\
-0.545\end{array}$} & \multirow{2}{*}{$\begin{array}{l}\text { Sig. } \\
0.587\end{array}$} \\
\hline & & -0.178 & 0.326 & & & \\
\hline & $\begin{array}{l}\text { Communication of energy conservation } \\
\text { and efficiency strategies }\end{array}$ & 0.642 & 0.067 & 0.694 & 9.644 & 0.000 \\
\hline & Energy efficiency and conservation strategies & 0.375 & 0.097 & 0.278 & 3.861 & 0.000 \\
\hline
\end{tabular}

Table 5. Summary of the model on renewable energy and reduction in energy costs.

\begin{tabular}{lcccc}
\hline Model & $R$ & $R^{2}$ & Adjusted $R^{2}$ & Std. error of the estimate \\
\hline 1 & $0.889^{a}$ & 0.790 & 0.786 & 0.675 \\
\hline$a=$ Predictors: (Constant), Communication of renewable energy strategies, $R=$ Multiple correlation coefficient, std. $=$ Standard. \\
\hline
\end{tabular}

Table 6: The ANOVAa of communication of renewable energy strategies and reduction in energy costs.

\begin{tabular}{lcccccc}
\hline Model & Parameter & Sum of squares & $d f$ & Mean square & $F$ & Sig. \\
\hline 1 & Regression & 94.277 & 1 & 94.227 & 207.003 & $.000^{\mathrm{b}}$ \\
& Residual & 25.036 & 55 & .455 & & \\
& Total & 119.263 & 56 & & &
\end{tabular}

$a=$ dependent variable: Implementation of the energy strategies resulted in a decrease in energy costs; $b=$ Predictors: (Constant), Communication of renewable energy strategies.

Table 7: Coefficients of the communication of renewable energy strategies and reduction in energy costs.

\begin{tabular}{|c|c|c|c|c|c|c|}
\hline Model & Parameter & & $\begin{array}{l}\text { dised } \\
\text { nts }\end{array}$ & $\begin{array}{l}\text { Standardised } \\
\text { coefficients }\end{array}$ & $t$ & Sig. \\
\hline 1 & (Constant) & 0.231 & 0.173 & & 1.333 & 0.188 \\
\hline & $\begin{array}{l}\text { Communication of renewable } \\
\text { energy strategies }\end{array}$ & 0.864 & 0.060 & 0.889 & 14.388 & 0.000 \\
\hline
\end{tabular}




\section{Conclusions}

Energy conservation, efficiency and renewable energy strategies are a vital part of all organisational management. It is important for organisations to implement all three strategies as part of an overall energy management strategy to reduce energy costs as well as greenhouse gas emissions. Other benefits from implementing energy management strategies include increased corporate social responsibility, increased energy security, possible tax reductions and protecting the environment. The two main barriers against implementing energy strategies include the costs of the strategies, as well as limited awareness and knowledge of the various energy strategies available. Most organisations implemented energy conservation and efficiency strategies, and that most of them were effective at reducing energy costs. However, renewable energy strategies are still lagging, although it was indicated that these strategies can assist organisations in reducing their energy costs. Although there is some form of internal communication regarding these energy strategies, there is room for improvement. This could be one of the key areas that organisations could concentrate on to make employees aware of their energy management strategies, which in turn could lead to a cost-effective approach towards energy risk management. In addition, it is recommended that education and training on energy strategies should make up an integral part of an organisation's risk management process to exploit the benefits that are linked to these strategies and to ensure the involvement of all the employees and stakeholders. It could also be recommended that awareness campaigns should be launched to promote the use of renewable energy strategies, thus ensuring that South Africa positively contributes to the global objective of reducing emissions.

\section{References}

Ates, S.A. \& Durakbasa, N.M. 2012. Evaluation of Corporate Energy Management Practices of Energy Intensive Industries in Turkey. Energy, 45(1): 81-91. http://dx.doi.org/10.1016/j.energy.2012.03.032.

Botha, E. 2017. A structured approach to energy risk management. PhD Thesis. University of South Africa.

Cassell, M. 2013. African renewable energy review. Johannesburg: Nedbank Capital.

Davidson, O., Tyani, L. \& Afrane-Okesse, Y. 2002. Climate change, sustainable development and energy: Future perspectives for South Africa. OECD. Energy and Development Research Centre,University of Cape Town, Cape Town, South Africa. Available at: http://www.erc.uct.ac.za/sites/default/files/image_tool/1 mages/119/Papers-pre2004/03-Davidson-

Winkler_SA_Energy_Future.pdf.

Department of Energy. 2016. Post-2015 national energy efficiency strategy. Government Gazette, (40515):
426-471. Available at: https://cer.org.za/wp-content/uploads/2017/01/National-Energy-EfficiencyStrategy.pdf.

Department of Energy. 2015. State of renewable energy in South Africa. Available at:

http://www.energy.gov.za/files/media/Pub/State-ofRenewable-Energy-in-South-Africa.pdf [Accessed January 12, 2016].

Dresselhaus, M.S. \& Thomas, I.L. 2001. Alternative Energy Technologies. Nature, 414(6861): 332-337. Available at: http://www.ncbi.nlm.nih.gov/pubmed/11713539.

Edkins, M.A.X., Marquard, A. \& Winkler, H. 2010. South Africa's renewable energy policy roadmaps. Energy Research Centre, University of Cape Town, Cape Town, South Africa.

Energy Lens. 2014. The what, why, and how of energy management. Available at: http://www.energylens.com/articles/energy-management [Accessed August 29, 2014].

Esty, D.C. \& Simmons, P.J. 2011. The green to gold business playbook: How to implement sustainability practices for bottom-line results in every business function. Chichester:Wiley.

Fox, E. 2009. Understanding sustainable energy practices : An analysis of alternative energy options at Simon Fraser University: 1-28.

Herring, H. \& Roy, R. 2007. Technological Innovation, Energy Efficient Design and the Rebound Effect. Technovation, 27(4): 194-203. Available at: http://www.sciencedirect.com/science/article/pii/S016 649720600112X [Accessed June 22, 2015]

Hsu, C.W., Chang, P.L. \& Hsiung, C.M. 2011. Construction and Application of a Performance Assessment Model for Energy Conservation and Carbon Reduction Industries. International Journal of Hydrogen Energy, 36(21):14093-14102. Available at: http://linkinghub.elsevier.com/retrieve/pii/S03603199 11010299 [Accessed September 25, 2014].

International Energy Agency(IEA). 2015. Statistics: South Africa 2015. Statistics. Available at: http://www.iea.org/statistics/statisticssearch/report/?ye ar $=2015 \&$ country $=$ SOUTHAFRIC $\&$ product $=$ Balan ces.

Johansson, M.T. \& Thollander, P. 2018. A Review of Barriers to and Driving Forces for Improved Energy Efficiency in Swedish Industry- Recommendations for Successful in-house Energy Management. Renewable and Sustainable Energy Reviews, 82(September 2017): 618-628. Available at: http://dx.doi.org/10.1016/j.rser.2017.09.052.

Keho, Y. 2016. What Drives Energy Consumption in Developing Countries? The Experience of Selected African Countries. Energy Policy, 91(December 2015): 233-246. Available at: http://dx.doi.org/10.1016/j.enpol.2016.01.010.

Lund, H. 2007. Renewable Energy Strategies for Sustainable Development. Energy, (32): 912-919.

Quaschning, V. 2009. Renewable energy and climate change. Chichester: Wiley. Available at: https://books.google.co.za/books?hl=en\&lr=\&id=JL 1BCL7GyBUC\&oi=fnd\&pg=PR5\&dq=renew- 
able + energy + and + climate + change \&ots $=$ inCGfYkl JY\&sig=2P0Q-LFES-Fg5_SNSdM6nSZkaV4

[Accessed August 19, 2015].

Russian Sustainable Energy Financing Facility (RUS-

EFF). 2011. Best Practice Guide for Energy

Efficiency. Russia

Small, D. 2012. Renewable energy: the right risk partner makes the difference.New York, NY:ACE Group. United States.

U.S. Energy Information Administration. 2013. Annual energy outlook 2013. Washington DC. Available at: www.eia.gov/forecasts/aeo.

U.S. Energy Information Administration. 2016.

International energy outlook 2016. Washington DC. Available at:

www.eia.gov/forecasts/ieo/pdf/0484(2016).pdf.

Winkler, H. 2005. Renewable Energy Policy in South Africa: Policy Options for Renewable Electricity. Energy Policy, 33(1): 27-38. Available at: http://linkinghub.elsevier.com/retrieve/pii/S030142150300195 2 [Accessed July 21, 2014].

Winkler, H. \& Van Es, D. 2007. Energy Efficiency and the CDM in South Africa : Constraints and Opportunities. Journal of Energy in Southern Africa, 18(1): 29-38. 